\title{
INCIDENCE AND CLINICAL PROFILE OF ANTI-N-METHYL-D-ASPARTATE RECEPTOR ENCEPHALITIS IN CHILDREN
}

\author{
Veerendra Kumar Madhavan Nair ${ }^{1}$, Savida Parameswaran ${ }^{2}$ \\ ${ }^{1}$ Associate Professor, Department of Paediatrics, Government Medical College, Parippally, Kerala. \\ 2Professor and HOD, Department of Paediatrics, Government Medical College, Kottayam, Kerala.
}

\begin{abstract}
\section{BACKGROUND}

Encephalitis in children is associated with high rate of morbidity and mortality. Many sporadic cases of encephalitis in children have recently been found to be CSF negative for infective markers. Antibodies against neuronal proteins in CSF are being detected more frequently in such patients and are well responsive to immunotherapy, if timely diagnosed. Anti-N-Methyl-D-Aspartate receptor (anti-NMDA) antibody mediated encephalitis is the most common in children among this group.
\end{abstract}

The objective of this study was to determine the incidence and clinical profile of anti-NMDA antibody mediated encephalitis in children and its early (6-8 weeks) and late (1 year) treatment responses.

\section{MATERIALS AND METHODS}

It was a descriptive study done in a tertiary care teaching hospital in south India. All children, 3 months to 12 years, presenting as acute encephalopathy, from January 2012 to December 2014 were evaluated and those with CSF anti-NMDA antibody positive children were treated with standard protocol and followed up at 6 weeks, 8 weeks and one year.

\section{RESULTS}

We had 178 children presented as acute encephalitis during the 3-year period. 18 (10\%) children were positive for anti NMDA antibody in CSF. Female gender predominated by $89 \%$. Predominant clinical features were in the descending order, behaviour and psychiatric $89 \%$, speech dysfunction $72 \%$, movement disorders $56 \%$, seizures $22 \%$ and autonomic phenomena $6 \%$. Majority (78\%) responded completely to immunotherapy.

\section{CONCLUSION}

Anti-NMDA receptor encephalitis is not rare in children. In children presenting as acute encephalitis with predominant neuropsychiatric symptoms or if CSF negative for infection, NMDA antibody test in CSF is a must. Prompt diagnosis is important because it is amenable to immunotherapy and longterm prognosis is very good.

\section{KEYWORDS}

NMDA, Encephalitis, Incidence, Clinical Profile, Autoimmune.

HOW TO CITE THIS ARTICLE: Nair VKM, Parameswaran S. Incidence and clinical profile of Anti-N-Methyl-D-aspartate receptor encephalitis in children. J. Evolution Med. Dent. Sci. 2016;5(97):7098-7100, DOI: 10.14260/Jemds/2016/1607

\section{BACKGROUND}

Encephalitis in children and adolescents is associated with a high rate of morbidity and mortality and poses difficult diagnostic and therapeutic challenges. The differential diagnoses are diverse, including infectious, immune, metabolic, genetic, traumatic, malignant and toxic disorders. Encephalopathy describes a clinical syndrome of altered mental status, defined as any alteration in arousal, cognition, speech or behaviour, lasting for 24 hours or more. ${ }^{1}$ Encephalitis means inflammation of the brain. It is strictly a pathological diagnosis; but surrogate clinical or imaging markers may provide evidence of inflammation including inflammatory changes in the cerebrospinal fluid or parenchymal inflammation on imaging. ${ }^{1}$ A period of up to 14 days was considered by consensus to define 'acute' encephalitis. $^{2}$

Financial or Other, Competing Interest: None.

Submission 31-10-2016, Peer Review 24-11-2016,

Acceptance 30-11-2016, Published 05-12-2016.

Corresponding Author:

Veerendra Kumar Madhavan Nair,

Lekshminivas, Shasthamkavu,

Karapuzha, Kottayam West P.0-686003. Kerala

E-mail:vkumarbabu@gmail.com

DOI: $10.14260 /$ jemds $/ 2016 / 1607$
The recent discovery that several forms of encephalitis result from antibodies against neuronal proteins has led to a definitive diagnosis in many of these cases. The antibodies target receptors and cell surface proteins involved in synaptic transmission, and associate with syndromes that despite being severe, frequently respond to immunotherapy. The resulting syndromes vary according to the antibody, with phenotypes that resemble those in which the function of the antigen is modified pharmacologically or genetically. The disorder most frequent in the paediatric population is anti-N-methyl-Daspartate (anti-NMDA) receptor encephalitis in which the antibodies target the NR1 subunit of the receptor. ${ }^{3}$

A multicentre study in the United Kingdom demonstrated that $4 \%$ of patients with encephalitis had NMDA receptor antibodies making this disorder the second leading cause of immune-mediated encephalitis, after acute disseminated encephalomyelitis. ${ }^{3}$ This disorder has become a leading cause of autoimmune encephalitis in children and adolescents, with $40 \%$ of patients being younger than age 18 years.3.It may present as a paraneoplastic syndrome in ovarian and testicular tumours, neuroblastoma, and Hodgkin lymphoma. ${ }^{2,3}$

\section{MATERIALS AND METHODS}

It was a descriptive study, done in a teaching hospital with tertiary care facilities. Objectives of the study were: (1) 
incidence of anti-NMDA antibody positivity among children, 3 months to 12 years, presenting as acute encephalopathy; (2) clinical profile, initial treatment response and one year neuropsychiatric status of the affected children.

Children with pre-existent neurological illness, acute poisoning, post-immunisation and post-traumatic cases were excluded from the study.

All children with acute Encephalopathy, between 3 months to 12 years age, during the study period, from January 2012 to December 2014 were enrolled. Cerebrospinal Fluid [CSF] analysis was done in all cases which included viral markers. CSF anti-NMDA receptor antibody by indirect immunofluorescence testing was done if CSF was negative for viral markers or if CSF had normal cytology and biochemistry. Those children with CSF anti-NMDA antibody positive were taken up for analysis. Detailed clinical features were noted. EEG, MRI brain and spine were done in all possible cases. Tumour screening was also done clinically and sonologically. All children were treated with standard treatment protocol for autoimmune encephalitis. ${ }^{4}$ Initial treatment response was assessed at 6 weeks and 8 weeks from the beginning of immunotherapy and was defined as complete if normal sensorium, normal motor functions, no seizures and no abnormal movements noted; otherwise recorded as partial, no response or death as the case might be.

All children who survived were followed up to one year (Late treatment response), for any relapses and treatment complications. At the end of 12 months, detailed general examination, neurological and psychological assessments were done. In children 5 years and above, with cognitive dysfunction, IQ (intelligence quotient) and below 5 years DQ (development quotient) were also assessed to find out the degree of disability.

\section{RESULTS}

During the study period, there were 178 cases of a/c encephalopathy, of which 18 were positive for anti-NMDA antibodies, showing an incidence of $10 \%$. Age ranges between 6 to 12 years with a median age of 9 years. Female gender is more affected, 16 children (89\%) were female.

Clinical and laboratory features were shown in table-1. Major presenting features were psychiatric symptoms as irritability, emotional instability, temper tantrums, aggressive behaviour, delusions, depression and hallucinations followed by non-fluent aphasia and dyskinetic movements. All children with dyskinetic movements had orofacial dyskinesia and $44 \%$ had additional, dystonic posturing and 33\% choreoathetoid movements of the limbs. Autonomic features of hypotension and hypoventilation and excessive sleepiness was noted in the first week of admission only in one child and she expired in spite of adequate treatment.

CSF was normal for microscopy and biochemistry in 67\% children, but protein was raised in the range of 70-200 $\mathrm{mg} \%$ in 5 children and one child had in addition to raised protein, pleocytosis as 50 lymphocytes/cu. mm. All the CSF samples were negative for viruses.

EEG was normal in 59\% cases. Out of the 7 abnormal EEGs, 4 had background slowing with multifocal spikes and 3 had only background slowing.

Imaging was normal in $82 \%$ children. Three children with abnormal MRI, were with frontal and medial temporal signal changes.
EEG and imaging could not be conducted in one child who expired in the acute phase.

All patients received steroid and IV Immunoglobulin; 10 (56\%) children received rituximab and cyclophosphamide. Plasma exchange was not done in any child due to unavailability of paediatric filter. Majority (78\%) recovered with fourth dose of rituximab.

Details of initial treatment response and one year posttreatment neuropsychiatric status were shown in table 2.

$56 \%$ children had complete and $39 \%$ had partial recovery in 6 weeks' time. In next 2 weeks' time, another $22 \%$ also completely recovered so that $78 \%$ completely recovered. 3 children who had only partial recovery at 8 weeks never improved in one year followup. One child with autonomic manifestations died in the first 6 weeks.

The partially recovered three children had moderate cognitive dysfunction and one child of the three who is the youngest in our cases, 6 year of age, had quadriparesis also. This is the only child with pyramidal tract involvement in our study. Two children had non-CNS complications during treatment; one had diabetes mellitus and one had hypertension, both of which eventually recovered before one year, once steroids were stopped.

\begin{tabular}{|c|c|}
\hline \multicolumn{2}{|c|}{ Clinical and Laboratory Features (Total No. 18*) } \\
\hline Age Group and Gender & 6-12 yrs. \\
\hline Female & $16(89 \%)$ \\
\hline Male & $2(11 \%)$ \\
\hline \multicolumn{2}{|l|}{ Clinical Features } \\
\hline Behaviour/Psychiatric Symptoms & $16(89 \%)$ \\
\hline Speech dysfunction & $13(72 \%)$ \\
\hline Dyskinetic movements & $10(56 \%)$ \\
\hline Seizures & $4(22 \%)$ \\
\hline Autonomic Features & $1(6 \%)$ \\
\hline \multicolumn{2}{|l|}{ [Hypotension, Hypoventilation] } \\
\hline \multicolumn{2}{|l|}{ Laboratory Features } \\
\hline EEG* Normal & $10(59 \%)$ \\
\hline Abnormal & $7(41 \%)$ \\
\hline CSF Normal & $12(67 \%)$ \\
\hline Abnormal & $6(33 \%)$ \\
\hline MRI* Normal & $14(82 \%)$ \\
\hline Abnormal & $3(18 \%)$ \\
\hline \multicolumn{2}{|c|}{$\begin{array}{l}\text { Table 1. }{ }^{*} \text { EEG and MRI could not be done in One Child } \\
\text { who Expired }\end{array}$} \\
\hline
\end{tabular}

\begin{tabular}{|c|c|c|c|}
\hline Time & $\begin{array}{c}\text { Complete } \\
\text { recovery }\end{array}$ & $\begin{array}{c}\text { Partial } \\
\text { Recovery }\end{array}$ & Death \\
\hline 6 Weeks & $10(56 \%)$ & $7(39 \%)$ & $\begin{array}{c}1 \\
(5 \%)\end{array}$ \\
\hline 8 Weeks & $14(78 \%)$ & $3(17 \%)$ & \\
\hline $\begin{array}{c}\text { One } \\
\text { Year }\end{array}$ & $14(78 \%)$ & $3(17 \%)$ & \\
\hline \multicolumn{3}{|c|}{$\begin{array}{c}\text { Table 2. Initial and Late Treatment } \\
\text { Response (total no. =18) }\end{array}$} \\
\hline
\end{tabular}




\section{DISCUSSION}

Autoimmune encephalitis is not a rare disorder. We had an incidence of $10 \%$ while previous studies showed only $4 \% .3,5$ We should start checking for antibodies in CSF in all children with encephalopathy symptoms, then more and more cases could be unearthed. Females are predominantly affected. Anti$\mathrm{N}$-methyl-D-aspartate (NMDA) receptor encephalitis is a diffuse central nervous system disease process characterised by dysfunction of subcortical structures, limbic regions, amygdalae, and frontostriatal circuitry. 6,7 Clinically, it has a gradual progression and good recovery. Main area of brain involvement is limbic system, so that pyramidal tract involvement and residual motor deficits are less common. ${ }^{7}$ In our series, only one child had pyramidal involvement.

This type of encephalitis usually presents with prominent psychiatric symptoms, dysphasia, movement disorders, hypoventilation, reduced consciousness and autonomic instability. Patients may be diagnosed mistakenly with a primary psychiatric disorder. The clue for autoimmune encephalitis is that it is usually never monosymptomatic. ${ }^{8}$ One additional feature was there for each affected child in our series, like movement disorder, dysphasia, altered sensorium or seizures, other than psychiatric symptoms. Monosymptomatic presentation either as behaviour changes or seizures or movement disorders alone are also reported in studies. ${ }^{8}$

Anti-NMDA encephalitis is well amenable to immunotherapy. ${ }^{9}$ Longterm outcome is good. ${ }^{2,9}$ In our study, $78 \%$ had complete recovery. That is the importance of checking NMDA antibody in CSF.

Clinical status at 8 weeks followup period and at one year are almost same indicating that by 8 weeks' time after onset, we can predict the final outcome. At presentation and up to one year followup, none of our cases had any tumour association. In other studies also, tumour association in children were less. Up to twenty percent relapses were reported in previous studies, ${ }^{10}$ but we had none.

In majority of cases, spinal fluid was normal for microscopy and biochemistry as well as imaging and encephalogram were also noncontributory for precise diagnosis.

In conclusion, due to the good treatment response and longterm outcome, we should send CSF for antibody testing in all encephalitic cases especially if presentation is with neuropsych symptoms or if CSF otherwise normal for routine tests and negative for viral tuberculous markers.

\section{What this study adds}

1. NMDA receptor encephalitis is not a rare disease; occupies $10 \%$ of acute encephalitis.

2. It is not a monosymptomatic illness; in addition to behaviour changes, abnormalities in speech, sensorium, movements will also be found.
3. Seizures and pyramidal involvement are less common.

4. Involvement of autoimmune system shows bad prognosis.

5. Eight-week outcome is comparable to that at one year.

6. With treatment, longterm outcome is good.

7. CSF examination for anti-NMDA antibodies is useful in acute encephalitis if no infective aetiology is established.

\section{REFERENCES}

1. Kneen R, Michael BD, Menson E, et al. Management of suspected viral encephalitis in children - Association of British Neurologists and British Pediatric Allergy, Immunology and Infection Group National Guidelines. J Infect 2012;64(5):449-77.

2. Sharma S, Mishra D, Aneja S, et al. Consensus guidelines on evaluation and management of suspected acute viral encephalitis in children in India. Indian Pediatrics 2012;49(11):897-910.

3. Armangue T, Petit-Pedrol M, Dalmau J, Autoimmune encephalitis in children. J Child Neurol 2012;27(11): 1460-69.

4. Chakrabarty B, Tripathi M, Gulati S, et al. Pediatric Anti-NMethyl-D-Aspartate (NMDA) receptor encephalitis: experience of a tertiary care teaching center from North India. J Child Neurol 2014;29(11):1453-9. http://jcn.sagepub.com/content/early/2013/10/03/08 83073813494474.

5. Shruthi TK, Shuba S, Rajkumar PS, et al. Anti-NMDA receptor encephalitis in an adolescent. Indian Pediatrics 2014;51(5):405-6.

6. Dalmau J, Gleichman AJ, Hughes EG, et al. Anti-NMDAreceptor encephalitis: case series and analysis of the effects of antibodies. Lancet Neurol 2008;7(12):1091-8.

7. Pinho J, Rocha J, Rodrigues M, et al. Diversity in anti-Nmethyl-D-aspartate receptor encephalitis: case-based evidence. Psychiatry and Clinical Neurosciences 2012;66(2):153-6.

8. Wright S, Hacohen Y, Jacobson L, et al. N-methyl-Daspartate receptor antibody-mediated neurological disease: results of a UK-based surveillance study in children. Arch Dis Child 2015;100(6):1-6.

9. Rosenfeld MR, Dalmau J. Anti-NMDA-receptor encephalitis and other synaptic autoimmune disorders. Curr Treat Options Neurol 2011;13(3):324-32.

10. Kruse JL, Jeffrey JK, Davis MC, et al. Anti-N-methyl-Daspartate receptor encephalitis: a targeted review of clinical presentation, diagnosis and approaches to psychopharmacologic management. Annals of Clinical Psychiatry 2014;26(2):111-9. 